\title{
El amor como acceso a la persona Un enfoque scheleriano del amor
}

\author{
ALBERTO SÁNCHEZ LEÓN \\ Universidad de Navarra (España) \\ asanleo@gmail.com
}

\begin{abstract}
Resumen
Pocos han sido los intentos de poner en el tapete filosófico la cuestión del amor como epígrafe necesario en el programa de una renovación de la historia de la filosofía. Sumariamente, prácticamente sólo San Agustín y tímidamente Pascal han hecho verdaderos esfuerzos al respecto. Quizá Platón atisbó mucho, pero no se atrevió a poner por escrito la naturaleza de la inteligencia del Bien. Para Platón aquello que es sagrado no es un objeto del conocimiento teorético, no es un axioma, sino que más bien tiene que ver con aquello que hace bueno al hombre, esto es el amor. Lo que hace bueno al hombre es la virtud, y la virtud nace del amor, pues el amor, como dice Platón, es engendrar en la belleza a causa del deseo de inmortalidad la virtud. Lo que engendra el amor es la virtud, la fuerza que transforma proviene del amor. De ahí que ya en Platón, en el viejo Platón se encuentra la idea de que lo más hermoso es hacer bueno al ciudadano, transformarlo. La perfección de la persona está en la virtud, y ésta es vástago del amor. La meta del presente trabajo mira a volver a tener una noción de la persona a partir del amor desde la perspectiva fenomenológica.
\end{abstract}

Palabras claves: amor, persona, Scheler, fenomenología.

\section{Love as access to the person Scheler's love approach}

\begin{abstract}
Very few philosophers have tried to deal with the question of love like a necessary subject to renew the History of Philosophy. Summing up those efforts, just Saint Augustine and, very shyly, Pascal have really tried. Perbaps Plato peered much, but he did not dare to write what was "The nature of intelligence of Good". For Plato, that what is sacred is not an object for theoretical knowledge, not an axiom, but rather it has to do with what makes a man good, that is love. What makes man good is virtue, and virtue comes from love. Love, as Plato says, is to generate in beauty because of the desire of immortality of virtue. What generates love is virtue; the power that transforms comes from Love. Hence, in the old Plato we find this idea: The most beauty thing is to make the citizen good, to transform him. A person's perfection is in virtue and this is the stem of Love. The aim of this paper is to go back to a notion of person from love from a phenomenological perspective.
\end{abstract}

Key words: Love, person, Scheler, Phenomenology.

Doctor en Filosofía por la Facultad Eclesiástica de Filosofía de la Universidad de Navarra. Licenciado en Teología por la Pontificia Universidad de la Santa Cruz de Roma. Ordenado sacerdote en Roma, el 23 de mayo de 2009. Entre sus publicaciones destacan los siguientes artículos: "Axiología y personalismo en la filosofía de Dietrich von Hildebrand" (2007), "La teodicea existencial en Leibinz" (2007), "Música y logos en la pervivencia del romanticismo. La concepción de la música en Nietzsche y Wagner" (2008) y "Cuando la palabra se pierde" (I) y (II) (2009), "Max Scheler y Leonardo Polo: Dos caminos diferentes con muchas afinidades” (2011). 


\section{Introducción}

En el panorama actual del pensamiento hay una disciplina (y hoy se pone en duda si es meramente una disciplina o algo más) que ha querido rescatar la cuestión del amor. Se trata de la fenomenología de corte realista. Más concretamente, pienso ahora en la filosofía de Hildebrand y Scheler, cuyo empeño en dar al amor su papel propio es verdaderamente una revolución de gran proyección en lo que a la historia del pensamiento se refiere. Ambos son conscientes, a pesar de sus diferencias, de que, de alguna manera, es necesario cambiar el rumbo filosófico. El amor es herramienta verdaderamente filosófica, aunque - estrictamente hablando- llamar al amor herramienta sea ya una aberración.

Muchos han visto, en este intento de poner el amor en el terreno filosófico, una mera protesta bien justificada. A mi juicio se quedan cortos en ver únicamente el esfuerzo de estos autores en mera denuncia. Hay algo más que una protesta, pues en ello nos va la ética y la antropología. Se trata de una propuesta, una invitación que es lo propio de toda índole filosófica: invitar a la verdad. Aunque tal invitación tenga un tinte trágico dado los tiempos que vive la filosofía. O ponemos el amor en el núcleo de estas disciplinas filosóficas o, entonces, hablamos de una ética y de una antropología que en nada dan razón del ser humano. La mera denuncia no basta, pues el amor va a ser para estos autores el acceso a la persona.

Como puede observarse-afirma Scheler-, esta teoría se distingue nítidamente en nuestro espíritu de todas las teorías, tanto de las de un primado de la razón como de las de un primado de la voluntad, por cuanto afirma un primado del amor y del odio tanto frente a todas las especies del 'representar' y del 'juzgar', como frente a todo 'querer'. Pues no corresponde, como se señaló en otra parte, subsumir en forma alguna los actos del interés, de la atención y los actos de amor y odio en el aspirar y querer, ni tampoco es posible reducirlos a meras modificaciones del contenido representativo ${ }^{1}$.

Con este trabajo pretendemos dar un mayor espacio filosófico al amor, quizás olvidado por la historia del pensamiento y despreciado por el acuciado academicismo reinante de los últimos siglos. Sin amor no cabe una entera comprensión de la persona humana, no cabe una antropología seria, y la fenomenología aquí tratada intenta un acceso a la persona que no podemos soslayar.

1 M. SCHELER: La esencia de la filosofía. Editorial Nova, Buenos Aires 1858, 35-36. 


\section{La lógica del amor}

Para tal proyecto es necesario primero rescatar la vida emocional y afectiva que tienen cabida en el maravilloso mundo de la subjetividad humana. Una vez abierta esta puerta de la vida emocional se puede observar con cierta nitidez que hay vivencias emocionales que gozan de un marcado carácter intencional. $\mathrm{Y}$, dentro de estas vivencias emocionales «el amor es el acto emocional básico, en el que se fundan los actos del preferir y postergar, así como la totalidad de los sentimientos de los que somos sujetos» ${ }^{2}$. Si el amor es tan importante para nuestros pensadores es porque realmente es guía de nuestras acciones. Esto implica cierta racionalidad ${ }^{3}$ o, como diría Pascal, esto requiere una «lógica del corazón»», pero una lógica que no puede reducirse a la lógica del entendimiento ${ }^{4}$. No es que sean opuestas, pero sí distintas. Para Scheler esta lógica del amor va a constituir la clave de su ética filosófica, pues de alguna manera, la esencia del hombre viene dada por lo que denomina ordo amoris ${ }^{5}$. «El amor es justamente la apertura a lo valioso de la realidad, de las cosas que nos rodean. El amor, dice Scheler, es un explorador o un guía que busca los valores, que es capaz de ir ampliando cada vez más la esfera de valores accesibles al hombre. El que

2 L. RODRÍGUEZ DUPLÁ: "La interpretación scheleriana del amor cristiano", en Gozo y Esperanza, Memorial Prof. Dr. Julio Ramos Guerreira, Publicaciones Universidad Pontificia Salamanca, Salamanca 2006, 892.

3 De ahí que Scheler utilice el término «amor comprensivo»: «Lo que, en primer término, nos proporciona la intuición de ese su ser ideal e individual de valor es la comprensión de su fuente más central, comprensión facilitada por el amor a la persona misma. Ese amor comprensivo es el gran constructor (...) el gran artista plástico que, de entre la mezcla de las distintas partes empíricas aisladas (...) es capaz de intuir y trazar las líneas de su esencia de valor», M. SCHELER: Ética. Nuevo ensayo de fundamentación de un personalismo ético. Caparrós editores, Madrid 2001, 635.

4 Cfr. M. SCHELER: Ordo amoris. Caparrós editores, Madrid 1996, 54-56.

5 Quisiera destacar tal noción agustiniana de ordo amoris, pues me parece conveniente. Desgraciadamente, parece ya un lugar común entre muchos filósofos hablar de cierta irracionalidad en el planteamiento scheleriano. Me parece una postura a veces ciertamente justificada debido a la ambigüedad con la que escribe el muniqués, unas veces a favor de la racionalidad, y otras, en contra de ésta. Esto hace que la investigación sea también un tanto confusa. Pero también puede ser una crítica injusta, pues la noción misma de ordo amoris nos dice algo de racionalidad. En efecto, ordo hace referencia a la inteligencia. El orden de las cosas hace posible la ciencia. Este orden que es jerarquía es expresión de una racionalidad ulterior, una razón fuerte (en contra del pensiero dèbole postulado por Vattimo que desde hace ya unos años vislumbra su ocaso), pues está direccionada por el amor. De modo que hablar de irracionalidad en el planteamiento scheleriano no está del todo justificado. Urbano Ferrer traduce con expresión orteguiana ordo amoris como el «fondo insobornable»; cfr. U. FERRER: ¿Qué significa ser persona? Palabra, Madrid 2002, 56. 
ama busca lo valioso en todos los órdenes: no sólo se complace en el valor sensible, sino que busca la belleza de la naturaleza, el resplandor de la verdad, el valor de la amistad...» ${ }^{6}$.

Se podría decir sencillamente que amar consiste en buscar más allá de nosotros aquello que nos hace mejores y hace a los demás mejores. «Ir más allá de sí mismo encontrándose a sí mismo pudiera ser una manera de definir el amor» ${ }^{7}$.

\section{La dinámica del amor}

Para Scheler el amor es fuente presente en el estrato superior de nuestra vida emocional intencional, pero al mismo tiempo es un movimiento que descubre valores más altos e incluso nuevos.

Siempre fue el amor para nosotros algo dinámico, un devenir, un crecer, un brotar de las cosas en la dirección de su prototipo que se halla en Dios (...). Todo amor es un amor hacia Dios, un amor todavía incompleto, frecuentemente latente o encaprichado, que al mismo tiempo precipita por sus caminos las cosas hacia Dios?

En este sentido no está lejos Scheler de la tesis agustiniana de que la virtud es el orden del amor: «El amor, que hace que se ame bien lo que debe amarse, debe ser también amado con orden, y así existirá en nosotros la virtud, que trae consigo el vivir bien. Por eso me parece que la definición más breve y acertada de virtud es ésta: la virtud es el orden del amon»?

Decir que la virtud es el orden del amor es decir que ella es la racionalidad del amor, es parte del amor, pero no sólo es amor, sino que piensa el amor, se recrea en él.

Este dinamismo propio del amor nos hace entender con más luminosidad que el amor es creativo, pues descubre los valores más altos encarnados en la persona amada. El movimiento del amor es la búsqueda de los valores, pero tal búsqueda no es el fin, pues entonces amaríamos a los valores de la persona y no a la persona en sí misma. Lo que sucede es

6 P. FERNÁNDEZ BEITES: “Amor en cuerpo y alma: Eros a la luz del ágape”, en J. R. Flecha (coord.): Dios es amor. Comentarios a la Enciclica de Benedicto XVI Deus caritas est, Universidad Pontificia de Salamanca, Salamanca 2007, 57-58.

7 M. GELABERT: "El cristianismo como oferta de sentido", en T. TRIGo (ed.), Dar razón de la esperanza. Homenaje al Prof. José Luis Illanes, Servicio de Publicaciones de la Universidad de Navarra, Pamplona 2004, 144.

8 M. SCHELER: Ordo amoris, 44.

9 SAn Agustín: De civitate Dei, lib. XV, cap. XXII. 
que a más conocimiento, a más enamoramiento de la persona amada, se descubre un universo lleno de valores que en la existencia fáctica estaba de algún modo velado precisamente por la carencia de amor. Por eso, el amor nos hace ver valores. «Y Scheler describe de nuevo el amor como un movimiento que, a partir de los valores dados ahora en la persona amada, busca los valores más altos. Por esta razón afirmamos que el amor es creativo, porque hace que aparezcan los valores más altos del amado. Dicho de modo más claro, no es cierto que el amor se limite a amar a la persona tal como es de hecho, con los valores que ya dispone. Lo peculiar del amor no es fijarse sólo en esto que ya es el amado, sino justamente en lo que puede llegar a ser, según la conocida sentencia de Píndaro: llega a ser el que eres» ${ }^{10}$. De ahí que Scheler afirme esta frase que encarna la noción misma de amor creativo, la cual no hay que entender como un amor que crea valores, sino que más bien hace ver, descubre, se recrea en los valores, pero no los crea:

El amor ama y ve en el amar algo más que lo que tiene y posee en sus manos. Puede fatigarse el impulso que lo desencadena; pero el amor mismo no se fatiga ${ }^{11}$.

El amor tiene a su vez tres formas de darse: el amor espiritual de la persona, el amor del yo individual y las pasiones o amor pasional. De los tres, el primero es el más puro pues es el amor entre espíritus, entre personas, que es, a su vez, el amor que hace ver los valores más altos. El amor personal se separa del yo. A la persona se accede desde sus actos sin pasar por el yo, de modo que el nivel del yo, es decir, sus cualidades respecto al mundo externo o sus reacciones emocionales no rozan el nivel espiritual del acto personal, y este solo se reconoce por la dirección de valor que está inscrita en el ordo amoris ${ }^{12}$.

Que el hombre ame una cosa, un valor, como el valor del conocimiento, que ame la naturaleza en esta o en la otra parte suya, que ame a un hombre como amigo, u otra cosa cualquiera: esto quiere decir siempre que sale de sí

10 P. FERnÁndez Beites: “Amor en cuerpo y alma: Eros a la luz del ágape”, 59. Cfr. S. SÁNCHEZ-MigALlón: La persona humana y su formación en Max Scheler. Eunsa, Pamplona 2006, 75.

11 M. SCHELER: Ordo amoris, 49. En otro texto scheleriano descubrimos la misma idea: «Justo en el hecho de que el amor es un movimiento en dirección hacia el ser-máselevado de los valores estriba su significación creadora (que también ya había sido reconocida por Platón). Esto no significa que el amor sea el que crea los valores mismos o el ser-más-elevado de los valores», M. SCHELER: Gramática de los sentimientos. Lo emocional como fundamento de la ética. Crítica, Barcelona 2003, 52-53.

12 Cfr. U. FERRER: ¿Qué significa ser persona?, 59. 
mismo, de su centro personal como unidad corpórea, y que coopera por medio de esta acción a afirmar, a impulsar, a bendecir esta tendencia hacia su peculiar perfección, que existe en los objetos que le rodean ${ }^{13}$.

De ahí el carácter vocacional del amor. El amor llama a vivir unos valores. «El ordo amoris individual será el que marca a cada hombre una vocación, una llamada. Cada persona tiene su propio deber, que le 'llama' sólo a él $\gg^{14}$, y en este sentido cabe hablar de un amor que es salvación, una salvación personal. En esa vocación cumplida el hombre encuentra su salvación ${ }^{15}$. «El acto por el que la persona logra la plena comprensión de sí misma, y merced a ello, la intuición y el sentimiento de su salvación, es el supremo amor a sí mismo» ${ }^{16}$. Esto es muy importante porque la vocación hace referencia al nombre de la persona. La vocación es la persona, y la vocación es personal. La vocación, a lo que está llamada la persona, es a su salvación, que es su plenitud. La llamada va unida al nombre: es pues sinónimo de persona, pues persona es nombre propio. De ahí que el ordo amoris es «privativo de cada persona. (...) los deberes que proceden de los valores a los que se refiere el ordo amoris de un individuo constituyen su vocación, la tarea moral que no puede delegar en ninguna otra persona» ${ }^{17}$. Cada persona tiene su vocación, su ordo amoris desde el que configura toda su existencia.

13 M. SCHELER: Ordo amoris, 44.

14 P. FERNÁNDEZ BEITES: “Amor en cuerpo y alma: Eros a la luz del ágape", 58.

15 Justamente en el amor ve Scheler la auténtica crítica a Lutero y al protestantismo en general cuando ponen su base en el miedo de conciencia, una actitud muy contraria al amor cristiano. «Lutero y Calvino sitúan la esencia de la contrición misma en los 'terrores conscientiae' en aquél miedo al infierno que se presenta a la vista de la falta de fuerza en el hombre para cumplir la ley. Según Lutero, para el hombre que siente el peso de sus pecados y su necesaria insuficiencia ante la ley de Dios, este temor es el único motivo eficaz para asegurarse de la justificación, mediante la fe en la Sangre expiatoria de Jesús y en la satisfacción y misericordia de Dios alcanzada por esa Sangre», M. SCHELER: Arrepentimiento y nuevo nacimiento. Encuentro, Madrid 2008, 32. Por otro lado, cuando Scheler habla de salvación personal a veces se refiere a que uno se salva a sí mismo, que es el arrepentimiento moral, y, otras se refiere a la trascendencia que supone hablar de vocación, esto es, al arrepentimiento en sentido religioso. Desde este último sentido, el hombre es salvado, no se salva, y es justamente salvado por los valores encarnados en la persona, que en última instancia remiten a la Persona Divina.

16 M. SCHELER: Ética, 640. Nótese también aquí que Scheler identifica amor con comprensión, con conocimiento.

17 L. RODRÍGUEZ Duplá: "La interpretación scheleriana del amor cristiano", en Gozo y Esperanza, Memorial Prof. Dr. Julio Ramos Guerreira, 894. 
Es muy significativo que Scheler hable del amor a las cosas como la aspiración suprema del hombre, pero ese amor debe ser además lo más parecido a como Dios ama ${ }^{18}$.

\section{El amor como fuente}

Así pues, el ordo amoris es lo que está detrás de cada acción humana moralmente relevante.

Porque es el medio de hallar tras los embrollados hechos de las acciones humanas moralmente relevantes, de los fenómenos de expresión, de las voliciones, costumbres, usos y obras espirituales, la sencilla estructura de los fines más elementales que se propone, al actuar, el núcleo de una persona, la fórmula moral fundamental según la cual existe y vive moralmente este sujeto. Por tanto, todo lo que podemos conocer nosotros de moralmente valioso en un hombre o en un grupo tiene que reducirse -mediatamente- a una manera especial de organización de sus actos de amor y de odio, de sus capacidades de amar y de odiar: al ordo amoris que los domina y que se expresa en todos sus movimientos ${ }^{19}$.

Otra peculiaridad del amor es que no sólo es fuente, sino que también es fin y motivo del obrar. Podríamos decir, con Aristóteles, que, en este sentido, el principio es también fin. El amor es principio y fin. Es más, podríamos hablar de una identificación del ser de la persona con su amor, pues en palabras de San Agustín uno se transforma en aquello que ama: ¿Amas la tierra? Serás tierra. ¿Amas a Dios? Entonces yo digo, serás Dios. Y también Santo Tomás nos dice lo mismo que San Agustín cuando dice que la caridad es el principio operativo de cada acción ${ }^{20}$. No es otra cosa lo que queremos expresar con la noción de disposición de ánimo de los autores expuestos.

La identidad está pues en lo más íntimo de nuestro ser y que lo hemos designado en otro lugar con la palabra corazón ${ }^{21}$. Pero esto parece

\footnotetext{
18 Cfr. M. SCHELER: Ordo amoris, 23.

19 Ibíd., 23.

20 Cfr. P. J. WADELL: La primacía del amor. Palabra, Madrid 2002, 81.

21 No en vano Scheler dice que la esencia del amor es el sursum corda, cfr. M. SCHELER: Ordo amoris, 49. La esencia del amor, el levantar el corazón (sursum corda) es, de alguna manera, el jerarquizar mis prioridades en la acción, es decir, poner en marcha el propio amor que ama en su orden. Y justamente poner en marcha el amor en su debido orden es la virtud. De hecho, Scheler habla de delirio cuando justamente el orden del amor se estanca. Ese estancamiento o trastorno del amor es la fuente del vicio y del encaprichamiento, noción que ya vimos a la hora de ver el motivo como fundamento de la
} 
una contradicción, pues, si es verdad que el amor es lo más íntimo, entonces, ¿cómo es posible que el amor sea un salir de sí mismo si es algo tan interior?

Esta dialéctica, no en sentido hegeliano, del amor, la dialéctica de la inmanencia y trascendencia del amor arraiga en la identidad del ser humano, un ser que es pura interioridad y, al mismo tiempo, un trascender continuo: un ser que es, en definitiva, espíritu amante.

El amor es un movimiento que va del valor más bajo al más alto ${ }^{22}$, el sursum corda, la elevación del corazón. Sólo desde este realce del corazón es posible seguir amando, y sólo desde el amor es posible llegar a la persona, pues el amor descubre sin objetivar al otro yo que ama, y en cuanto que ama ya no es yo sino espíritu, persona. «La persona sólo es accesible al amor, que es el que la desvela, siendo este amor recíproco: supone de parte de la persona la apertura a los demás. Pero, ¿cómo puede sernos dada la persona si es cierto que ninguna clase de saber nos la descubre? «La persona sólo puede dársenos 'co-ejecutando' sus actos, cognoscitivamente en el 'comprender' y el 'vivir lo mismo'; moralmente en el seguir el ejemplo’» ${ }^{23}$.

Es Scheler mismo quien dice:

Por esto fue siempre el amor, para nosotros, el acto radical y primario por el cual un ente, sin dejar de ser tal ente limitado, se abandona a sí mismo para compartir y participar como ens intentionale en otro ente, sin que por esto se conviertan ambos en partes reales de nada ${ }^{24}$.

Si el amor es un salir de sí, la dirección de tal salir es otro yo, o propiamente el prototipo. Es por ello que, si como dice Scheler, todo amor es un amor hacia Dios, entonces, hasta que no lleguemos a Él, nuestro amor es un amor incompleto. El prototipo último es Dios, y también la persona sólo puede mirarse a sí misma a través de Él, por eso dice Scheler que «la persona se gana perdiéndose en Dios» $»^{25}$.

\footnotetext{
voluntad. «Vamos a llamar a esta forma, la más general de la destrucción y trastorno del ordo amoris, a la cual se pueden reducir en cierto modo sus formas más especiales, encaprichamiento, un vocablo que designa de la manera más plástica tanto la seducción que un bien finito cualquiera ejerce sobre el centro rector de su persona, como el carácter delirante de este comportamiento», M. SCHELER: Ordo amoris, 51.

22 También Platón definía en el Banquete el amor como un movimiento que se dirige al ser desde el no-ser.

23 A. PINTOR Ramos: El humanismo de Max Scheler. Biblioteca de Autores Cristianos, Madrid 1978, 257.

24 M. SCHELER: Ordo amoris, 44.

25 M. SCHELER: Amor y conocimiento y otros escritos. Palabra, Madrid 2010, 34.
} 
En cuanto que el prototipo aparece en la dinámica del amor, entonces se puede decir que el amor es, por ello, fuente de la vida moral, pues, el prototipo es motivo, mueve, inicia el movimiento. Ahora bien, en cuanto que la tarea ética estriba en llegar a identificarnos con el prototipo, entonces el amor es fin. En todo caso, cabe describir al hombre como un ser que busca, que ama, de ahí la famosa sentencia scheleriana: «Antes de ens cogitans o de ens volens es el hombre un ens amans $^{26}$.

Con todo, parece que el amor, como ya sucedía con la noción de valor scheleriana, no es definible, pero sí descriptible: «En tanto que últimas esencias de los actos, el amor y el odio sólo pueden ser hechos intuibles, no definibles» ${ }^{27}$.

Bien es cierto que el amor tiene distintas acepciones. Tal vez haya sido Dietrich von Hildebrand quien haya estudiado más a fondo y de modo sistemático lo que constituye la esencia del amor. Querría subrayar ahora el punto de partida que Hildebrand toma para estudiar el amor, y es que no puede ser otro que el del acto de amar. En efecto, se parte del acto de amor tal como se nos da, de nuestra experiencia de amar. Y con ello se llega a la primera tesis, a saber, que el amor es una respuesta al valor. De lo dicho se sigue que el amor no es un mero apetito, pues en el apetito el objeto apetecido sólo es relevante, en el sentido de importancia, en virtud de mi apetito. Por el contrario, en el amor, la importancia del objeto está en él mismo, es importante en sí mismo.

Pero, además, el amor es una respuesta dirigida a la persona. «El amor en su sentido más propio e inmediato es el amor a otra persona, el amor al otro -el amor materno, el amor del niño a los padres, el amor esponsalicio, el amor a Dios o el amor al prójimo» ${ }^{28}$. Por tanto, la temática del amor no es el valor, sino la persona amada. Así que de nuevo nos topamos con el personalismo ético que late en los autores que estamos tratando.

Efectivamente, no amamos a los valores sino a las personas, aunque ese amor es suscitado por valores que encuentro en esa persona que amo. Esta tesis hildebrandiana en nada desdice la noción de seguimiento scheleriana.

La tesis escuetamente expuesta de Hildebrand sobre el amor como respuesta al valor presupone un conocimiento del valor y hace a la vez

\footnotetext{
26 M. SCHELER: Ordo amoris, 130.

27 M. SCHELER: Gramática de los sentimientos, 50. Algo semejante le sucede a la noción de persona. Sobre la indefinibilidad de la persona, cfr. M. MORENO VILLA: El hombre como persona. Caparrós, Madrid 2005, 29-34.

28 D. VON HiLdEBRAND: La esencia del amor. Eunsa, Pamplona 1998, 47.
} 
que veamos el valor. Tal captación del valor en su inicio hace que, después, el sujeto de ese amor se capacite para una nueva y más profunda captación del valor. Y esta última, a su vez, fundamenta un nuevo y más profundo amor, y éste, por su parte, una nueva y más profunda captación del valor ${ }^{29}$. Podríamos pensar que esto es un círculo vicioso, pero preferimos ver en esto un círculo más bien virtuoso, pues en cuestiones como el amor, al no haber límites siempre cabe agrandar el círculo, pero no contraerlo.

\section{Identidad y vocación de la persona humana}

En el amor a nosotros mismos descubrimos nuestra Gesinnung (disposición de ánimo) como amando y tendiendo a un ideal valioso personal, como buscando nuestro puesto singular dentro del cosmos moral, en palabras de Scheler. Ese ideal nos es dado en una disposición de ánimo encarnada en otra persona ${ }^{30}$. Cuando éstos valores se nos presentan en esa persona ideada o existente, entonces reconocemos aquello que nos falta para llegar a ser quien queremos (debemos) ser. De ahí que no hay un deber general al que obedecer, sino un ideal al que seguir, al que amar. Pues bien, el amor es esa fuerza (virtus) que nos transforma y nos acerca al ideal. La persona es así puro crecimiento en el amor. «La identidad [de la persona] reside exclusivamente en la dirección cualitativa de ese puro tornarse otro» ${ }^{31}$.

En palabras de Leonardo Rodríguez Duplá: «Cuando Scheler afirma que el ordo amoris es el núcleo de la identidad personal, toma aquella expresión en un sentido normativo. Somos, a última hora, lo que estamos llamados a ser; lo que nos define como personas es nuestra vocación, nuestro yo ideal» ${ }^{32}$. Persona es, entonces, vocación, crecimiento desde nuestro ordo amoris fáctico al prototipo personal que en el seguimiento vemos, o, más bien, nos vemos. Somos, en este cierto sentido y como decía Ortega, futurización, es decir, aquello a lo que estamos destinados a ser. Y ello depende del uso de nuestra libertad.

$\mathrm{Si}$ lo que realmente somos lo sabemos con nuestra biografía, entonces, nuestra identidad, que la ha forjado la libertad de nuestras acciones guiadas por motivos, también es dinámica. Tan dinámica como nuestro ordo amoris. Esta es la peculiaridad de la libertad humana: su

\footnotetext{
29 Ibíd., 57.

30 S. SÁNCHEZ-MigALLÓN: La persona bumana y su formación en Max Scheler, 70.

31 M. SCHELER: Ética, 515.

32 L. RODRÍGUEZ DUPLÁ: "La interpretación scheleriana del amor cristiano", 893.
} 
constante dinamismo ${ }^{33}$ que hace que una persona sea ella en cada acción libre, y a la vez, sea también su prototipo. Su impronta en cada acción es su identidad. Y tal identidad será estable en la medida en que las acciones de la persona sean guiadas por el amor. Esto significa que la identidad estable lo da la vida virtuosa, o la vida que haya encarnado los valores que propone el prototipo. Por eso, se suele hablar en ética de hábitos, es decir, de un habituarse de la persona con su entorno y con los de su entorno.

Por la identidad de la persona - como puro crecimiento en el amor que ya vimos cuando hablamos del amor como fuente de vida moral-, podemos deducir que la tesis scheleriana no es actualista, ya que si ponemos la identidad en la libertad —una libertad que tiene sus múltiples matizaciones-, entonces es lógico pensar que no somos libres solamente cuando ejercemos este "poden», sino que lo somos por ser personas; por la tesis de que la persona es ordo amoris variable, no hay cosificación, y, por tanto, no cabe un substancialismo. ¿Cómo definir, entonces, a la persona?

El problema acerca de una definición de la persona es ya un lugar común entre los pensadores contemporáneos. Si hemos dicho que la persona está construyendo su esencia a través de su libertad, parece que la respuesta sobre una definición de persona es bastante problemática. Definir lo más dinámico, y además un dinamismo en crecimiento, es verdaderamente complejo. A una persona individual la puede definir (describir) su propia biografía, pero ¿es necesario dar una respuesta a la definición de la persona en su carácter general? A la persona podemos describirla y en tal descripción la vamos definiendo, perfilando, de ahí la importancia del método fenomenológico. En efecto, con la ayuda fenomenológica, con la perspectiva de la psicología descriptiva, Scheler acota la noción de persona, finalmente, como la concreta, esencial y entitativa unidad de actos de la más diversa esencia.

Sumario: Introducción; 1. La lógica del amor; 2. La dinámica del amor; 3. El amor como fuente; 4 . Identidad y vocación de la persona humana.

33 No es de extrañar que la libertad sea, por eso mismo, potencia, dinamis, poderhacer, pero un poder-hacer real. 